Juventud(es) y masculinidad(es) en la serie televisiva El Marginal. Un análisis socio-antropológico con perspectiva de género

Julieta Nebra

https://perio.unlp.edu.ar/ojs/index.php/question/article/view/4886

Cita sugerida: Nebra, J. (2018). Juventud(es) y masculinidad(es) en la serie televisiva El Marginal. Un análisis socioantropológico con perspectiva de género. Question, 1(60), e115. doi:https://doi.org/10.24215/16696581e115

\title{
Juventud(es) y masculinidad(es) en la serie televisiva El Marginal. Un análisis socio-antropológico con perspectiva de género
}

\author{
Youth and masculinity(ies) in the television series El Marginal. A \\ socio-anthropological analysis from a gender perspective
}

Julieta Nebra julinebra@hotmail.com

http://orcid.org/0000-0003-3835-5993

Instituto de Ciencias Antropológicas; Facultad de Filosofía y

Letras; Universidad de Buenos Aires/ Consejo Nacional de Investigaciones Científicas y Técnicas (Argentina)

\section{Resumen}

En este artículo se analiza el tratamiento de los jóvenes varones en la serie ficcional televisiva argentina El Marginal, situada en la cárcel San Onofre. Se hará foco en los jóvenes denominados en la serie como "sub 21" (por debajo de los 21 años de edad): cómo están personificados, cómo se relacionan entre ellos, con los adultos varones y con las mujeres dentro de la institución penal, entre otros, desde una perspectiva de género. Daremos cuenta de la representación de imágenes estereotipadas y simplificadas de la masculinidad de estos jóvenes en contexto de encierro. 
El enfoque es socio-antropológico y desde una perspectiva de género e interseccionalidad. El corpus de análisis comprende todos los capítulos de la primera temporada de la serie.

Palabras clave: Juventud; masculinidad; delito; representaciones; ficción.

\section{Abstract}

In this article we analyze the treatment of young males in the argentinian fictional television series El Marginal, located in San Onofre jail. The focus will be placed on thegroup of young males named as "sub 21" (below 21 years old): how they are personified, how they relate with each other, with male adults and with women within the penal institution among others, from a gender perspective. We identify that the representations and images of the masculinity of these young people are stereotyped and simplified.

The aproach of this study is socio-anthropological and from a gender perspective and intersectionality approuch. The corpus of analysis includes all the chapters of the first season of the series.

Keywords: Youth; masculinity; crime; representations; fiction.

Este artículo surge de un proceso de reflexión en torno a las representaciones sociales respecto de los jóvenes en conflicto con la ley penal y la construcción de masculinidad(es). El mismo se enmarca dentro de un proyecto de investigación doctoral más amplio sobre masculinidad, juventud, delito y políticas públicas. A su vez, se parte del antecedente de la tesis de maestría en Género, Sociedad y Políticas (1) (FLACSO) y de la participación en diversos equipos de investigación (UBACYT y PIG, carrera de Trabajo Social/UBA).

Para mi tesis de maestría, analicé mi experiencia como trabajadora social en una institución de privación de libertad para jóvenes varones entre 18 y 21 años de edad en conflicto con la ley penal, perteneciente a la Dirección Nacional de Adolescentes Infractores a la Ley Penal (DINAI), bajo la órbita del Ministerio de Desarrollo Social de la Nación (MDSN) de la República Argentina entre 2013-2014. En pleno proceso de escritura de tesis se estrenó la serie de televisión argentina El Marginal (Televisión Pública Argentina, 2016) situada en una institución penal. A partir de esta "coincidencia", me propuse relacionar mi investigación abocada a problemáticas sociales reales, con el modo en que la ficción reproduce o recompone dicho escenario. 
La serie El Marginal es un drama policial cuya historia transcurre principalmente dentro de la cárcel San Onofre, en la cual se desarrollan distintos personajes y relaciones principalmente delictivas y/o sexo afectivas. La misma fue escrita por Adrián Caetano, dirigida por Luis Ortega y producida por Underground Producciones. La primera temporada consistió en 13 episodios y se estrenó en la Televisión Pública Argentina el 2 de junio de 2016. Desde octubre de 2016, también se encuentra disponible en la plataforma de Netflix. La segunda temporada se estrenó el 17 de julio de este año por el mismo canal.

La misma ha sido galardonada con trece Premios Tato (2016), entre ellos al "Programa del año" y "Mejor ficción unitario", también a nivel internacional ha sido premiada en el Festival Series Manía (Francia, 2016) como "Mejor serie internacional" y en los Premios Martín Fierro (2017) ha recibido tres galardones, entre ellos el "Martín Fierro de Oro".

A partir de la mencionada coincidencia entre mi trabajo de investigación y el lanzamiento de esta serie televisiva con altos niveles de audiencia (para el promedio de la TV Pública Argentina), comencé a interesarme por comprender cómo la ficción presentaba y creaba esta realidad carcelaria, considerando que la misma se sitúa en un escenario realista y no inventado como podría ser la ciencia ficción. En este sentido los consumos culturales, como los productos audiovisuales en especial aquellos presentes en los medios masivos de comunicación, tienen un rol fundamental en la creación, reproducción o reconstrucción de estereotipos y representaciones sociales.

En este artículo, entonces, analizaremos las formas en las que se presenta el argumento de El Marginal (primera temporada) y haremos foco en particular en las representaciones de los jóvenes varones privados de su libertad. Por ende nos centraremos en los jóvenes denominados en la serie como "sub 21" (por debajo de los 21 años de edad): cómo están personificados, cómo se relacionan entre ellos, con los adultos varones y con las mujeres dentro de la institución penal, entre otros, desde una perspectiva de género.

\section{Consideraciones teórico-metodológicas}

El corpus de análisis abarca la totalidad de episodios (13) de El Marginal en su primera temporada estrenada en 2016. Las imágenes que se presentan en este trabajo son capturas de pantalla obtenidas a través de una plataforma virtual oficial, seleccionadas especialmente para este análisis. Como hemos mencionado, este trabajo se inscribe dentro de un proyecto de investigación más amplio sobre juventud(es), delito y masculinidad(es) y por ende nos 
centraremos entonces en el tratamiento de esta población en particular desde la antropología audiovisual y la perspectiva de género.

\section{Antropología audiovisual}

Según resultados difundidos por la encuesta Nacional sobre Acceso y Uso de Tecnologías de la Información y la Comunicación (INDEC/ENTIC) en Hogares y Personas, el 97\% de los hogares del país cuenta con, por lo menos, un aparato de televisión, seguido de la radio y el teléfono móvil. Es decir que es la TIC a la que accede casi la totalidad de la población argentina. Esto implica que los contenidos que se presentan en la televisión tienen la posibilidad de llegar a toda la población por igual, por ende las imágenes que se construyan sobre mujeres y varones llegarán tanto a comunidades rurales como a zonas urbanas, a estratos socioeconómicamente acomodados como también a los empobrecidos, a inmigrantes, habitantes de los pueblos originarios, argentinos/as, niños/as, adolescentes, jóvenes, adultos/as, ancianos/as, etcétera. De aquí se desprende la importancia que tienen los medios de comunicación, fundamentalmente la televisión, en la construcción de subjetividades, deseos, e imaginarios sociales.

Si a la masividad del acceso a la televisión en el país de origen de la serie, sumamos el fenómeno de la plataforma de streaming Netflix, que incorporó a El Marginal en sus contenidos, nos encontramos con un alcance masivo y globalizado de las imágenes y representaciones sobre el mundo carcelario que se propone desde la serie. La globalización es un proceso mediante el cual la información y las imágenes viajan a velocidades jamás pensadas y llegan a los lugares más remotos. Los/as personajes del mundo carcelario de la ficticia cárcel de San Onofre, son conocidos/as por televidentes provenientes de distintos sectores socioeconómicos y culturales, esto podría generar representaciones generalizadas de la cárcel, los presos y en el particular caso que nos interesa de los jóvenes delincuentes, las cuales cobrarán sentidos determinados de acuerdo a sus resignificaciones locales. En esta era donde la información y las imágenes se diseminan y se crean expectativas de consumo, se produce un efecto de "identificación colectiva" (Hopenhayn, 1999), en la que las series televisivas, las publicidades y las películas -entre otros- construyen sensibilidades, estéticas, formas de consumir y de ser.

Es en este sentido que la antropología audiovisual es un aporte fundamental a la hora de comprender los fenómenos sociales actuales y sus representaciones e imaginarios colectivos. La misma "(...) se centra en el estudio de la formación, gestión y expansión de constructos simbólicos, y el modo en que las representaciones sociales actúan como formas de percepción y traducción empírica de etnoconcepciones culturales" (Grau Rebollo, 2005: 2). Por ende el 
análisis de un producto cultural como lo es El Marginal, nos permitirá dar cuenta no solo de la producción cultural de una sociedad determinada, sino también, como la misma crea y recrea la realidad para la sociedad argentina y global de lo que es el mundo carcelario argentino. Considerando que la mayoría de la población no tiene acceso a estos espacios en la vida real, la ficción cobra una relevancia fundamental a la hora de construir significados en torno a los mismos. Por ende, podemos hablar de un proceso de refracción de la realidad y no de reflejo tal como propone Grau Rebollo:

(...) el efecto de verosimilitud se consigue cuando reconocemos la fuente original a través de su refracción. La realidad de un filme siempre será mediada, por cuanto el texto fílmico crea realidad, no simplemente la refleja (Buxó 1999). Su valor documental, en mi opinión, es doble. Por un lado parte de un patrón presuntamente normativo (y familiar para la audiencia) estudiable y analizable; pero por otro, y tal vez esta dimensión sea especialmente seductora desde la perspectiva intelectual, deforma ligeramente la cepa original mediante una mutación ideológica que nos sitúa ante una apasionante multidimensionalidad simbólica. Ese proceso intencional de refracción incorpora diversas estrategias narratológicas que no sólo se centran en la imagen, sino que incorporan el audio, la escenografía, la construcción del personaje, el uso de los colores, los diálogos, las referencias subliminales, etc. (Grau Rebollo, 2005: 4-5).

\section{Perspectiva de género, interseccionalidad, masculinidad(es) y juventud(es)}

El sistema sexo/género funciona como ordenador de las relaciones y jerarquías sociales entre las personas, delimitando a su vez las características que deben poseer las mujeres y varones, las formas de pensar, sentir, comportarse, etcétera. En este sentido guarda una relación intrínseca con la distribución del poder: "(...) Hasta el punto en que esas referencias establecen distribuciones de poder (control diferencial sobre los recursos materiales y simbólicos, o acceso a los mismos), el género se implica en la concepción y construcción del propio poder" (Scott, 1996: $s / p)$.

La perspectiva de género es una propuesta epistemológica de acercamiento a la realidad en tanto construcción social. Este enfoque entiende que para comprender el orden social, sus relaciones, luchas de poder e historia es imprescindible considerar el sistema sexo/género como parte constitutiva del mismo. En palabras de la historiadora Joan Scott “(...) el género es una forma primaria de relaciones significantes de poder. Podría mejor decirse que el género es el campo primario dentro del cual o por medio del cual se articula el poder" (Ídem). 
Entender que el género es parte de todas las relaciones sociales y de poder, y no solo de aquellas del mundo doméstico y de las relaciones sexo-afectivas heterosexuales, nos obliga a mirar absolutamente todas las actividades de los seres humanos desde esta lente. Las manifestaciones y producciones culturales tales como las series televisivas son un ejemplo de esto, ya que las mismas surgen dentro de un orden social constituido primariamente por el sistema sexo/género y porque a su vez reproducen y reconstruyen este orden mediante la transmisión de representaciones sociales.

Teresa de Lauretis comienza su libro Alicia ya no (1992) retomando un diálogo entre Humpty Dumpty y Alicia, el cual versa sobre el significado de las palabras y sobre quien detenta el poder para dotarlas de dicho significado:

"La cuestión es", dijo Alicia, "si usted puede hacer que las palabras signifiquen cosas tan diferentes".

"La cuestión es", dijo Humpty Dumpty, "quien es el amo-eso es todo." (de Lauretis, 1992: 9).

Para la autora, la clave está en actuar tal como lo hizo la protagonista del clásico cuento: interpelar los significados del lenguaje, cuestionarlos en lugar de aceptarlos educadamente. Los aportes de los estudios de género y/o feministas han sido más que relevantes para instalar estos interrogantes y así dar cuenta de la perpetuación de estereotipos en el lenguaje audiovisual, aunque en su mayoría se han centrado en las representaciones y tratamiento de las mujeres ya sea en publicidades, largometrajes y/o ficciones televisivas.

En este sentido, la(s) masculinidad(es) han quedado poco problematizadas si bien podemos mencionar trabajos de Argentina como el de Ana C. Ferreiro Habra (2018) quien analiza las masculinidades en el discurso publicitario y el de Florencia Cremona y Verónica S. Ficoseco (2015) quienes abordan el programa argentino Showmatch y destacan que este tipo de espectáculos "enseñan" una masculinidad heterosexual y violenta. En cuanto al análisis de las masculinidades de los productos culturales audiovisuales, se destacan en España los trabajos de Francisco Zurian (2015) quien compila una serie de trabajos que analizan las distintas masculinidades en las narrativas de la historia del cine y la televisión y Virginia Guarinos (2013; 2015) quien analiza en múltiples trabajos las representaciones de género en especial aquellas que titula como "nuevas masculinidades".

El mundo carcelario, como el representado en la serie El Marginal, es un espacio social en el cual se intersectan las condiciones socioeconómicas y las de género, ya que como dan cuenta los indicadores la mayoría de la población privada de su libertad son varones pobres -Rita Segato (2007) al analizar las cárceles de Brasil agregará, también, el componente racial-. A su 
vez, la población privada de su libertad en el país es en su mayoría joven: "La franja de los 18 a los 24 años de edad representa casi un tercio de la población penal total y, junto con la siguiente (hasta 34 años), alcanzan el 64 \%” (Parchuc, 2015: 21). Cabe destacar que existen numerosos trabajos que abordan la representación de los/as jóvenes en los medios de comunicación, en especial en las noticias, vinculados/as al delito y la violencia (Martinuzzi, 2011; Fernandez, 2012; Koziner, 2014, entre otros/as) pero son escasos aquellos que imbriquen la juventud y el delito desde una perspectiva de género para el análisis de una ficción.

Es por esto que a la perspectiva de género se suma el enfoque de interseccionalidad, acuñado por la referente del feminismo negro Kimberlé Crenshaw (1991), quien entiende que este enfoque no supone una sumatoria de desigualdades “(...) sino que cada una de éstas interseccionaban de forma diferente en cada situación personal y grupo social mostrando estructuras de poder existentes en el seno de la sociedad" (Expósito Molina, 2012: 210).

En este sentido, la relación entre la juventud, la clase social, y el género se intersecta y genera nuevas experiencias que no significan una sumatoria o "comatización" de las vivencias de cada dimensión mencionada, sino que construyen una particularidad situada. En el caso que venimos trabajando, abordamos la población de jóvenes en conflicto con la ley penal develando que son en su amplia mayoría varones y de sectores marginales y vulnerados.

Teniendo esto en consideración, tomamos el modelo teórico de Connel (1997) sobre masculinidades que permite problematizar y repensar la existencia simultánea y entrelazada de distintas formas de masculinidad, tales como la hegemónica, la subordinada, la marginal y la cómplice; superando visiones hegemónicas, esencialistas y homogeneizantes, que describen el "ser varón" de una sola manera. Y en esta línea, consideramos las implicancias de la(s) socialización(es) masculina(s) dependiendo de cómo se intersecten con otras dimensiones.

En este trabajo la interseccionalidad nos habilita a atravesar las dimensiones del grupo etario, el género y el sector social permitiéndonos develar las distintas formas de representar a los jóvenes de la "sub 21" en la serie televisiva El Marginal.

Connel postula que la masculinidad "(...) si se puede definir brevemente, es al mismo tiempo la posición en las relaciones de género, las prácticas por las cuales los hombres y mujeres se comprometen con esa posición de género, y los efectos de estas prácticas en la experiencia corporal, en la personalidad y en la cultura" (1997: 36). A su vez, considera al género como una forma de ordenamiento de la práctica social y de la vida cotidiana a partir del "escenario reproductivo" (no es base biológica), producto de la historia. También reconoce que las instituciones están provistas de género siendo el Estado una institución masculina, por un lado por una mayor cantidad de contrataciones de hombres y a su vez por la estructuración genérica 
de la práctica. El modelo de la estructura de género tiene tres dimensiones para la autora: por un lado las relaciones de poder (subordinación general de las mujeres y dominación de los hombres- patriarcado); las relaciones de producción (división genérica del trabajo, discriminación salarial) y las de cathexis (vínculos emocionales, relaciones y deseo sexual).

Finalmente identifica que hay distintas masculinidades y que las mismas se vinculan con las relaciones genéricas con las mujeres y entre los mismos hombres:

-Masculinidad hegemónica: refiere a la práctica genérica que garantiza la dominación del hombre sobre las mujeres.

- Masculinidad subordinada: refiere a una jerarquía de género entre hombres, vinculando la subordinación a lo "femenino", en especial -pero no únicamente- relacionado con la homosexualidad.

-Masculinidad cómplice: refiere a las prácticas genéricas que no encarnan el tipo de masculinidad hegemónica pero que garantizan a los hombres la obtención de un dividendo patriarcal;

-Masculinidad marginal: refiere a una jerarquía de género entre hombres, vinculando la subordinación con la raza y clase social.

Para esta autora, la violencia es la forma de sostener las relaciones de dominación de los hombres respecto de las mujeres y entre sí:

(...) la violencia llega a ser importante en la política de género entre los hombres. La mayoría de los episodios de violencia mayor (considerando los combates militares, homicidios y asaltos armados) son transacciones entre hombres. Se usa el terror como un medio de establecer las fronteras y de hacer exclusiones, por ejemplo, en la violencia heterosexual contra hombres homosexuales. La violencia puede llegar a ser una manera de exigir o afirmar la masculinidad en luchas de grupo. Este es un proceso explosivo cuando un grupo oprimido logra los medios de violencia -como se testifica en los niveles de violencia entre los hombres negros, contemporáneamente, en Sudáfrica y en Estados Unidos. La violencia de las bandas juveniles en ciertos sectores de las ciudades es un ejemplo notable de la afirmación de masculinidades marginadas contra otros hombres, que continúa con la afirmación de la masculinidad en la violencia sexual contra las mujeres (Connel, 1997: 45). 
Por ende, observar cómo se vinculan las practicas violentas con las representaciones de los jóvenes en la serie nos permitirá dar cuenta de la construcción de este imaginario particular, tal como analizaremos a continuación.

\section{La "sub 21" en El Marginal}

La serie gira en torno al personaje principal Miguel Palacios (Juan Minujín), un policía convicto que se infiltra en la cárcel de San Onofre bajo el nombre Pastor Peña, para averiguar sobre el secuestro de la hija de un juez -ya que se presume que el mismo está vinculado con una banda de internos al mando de "Los Borges"- y en retribución obtener la libertad. Pastor tiene una historia personal compleja vinculada al consumo de drogas y al abuso de poder policial por el cual termina preso, por estos motivos su hijo pequeño era cuidado por su hermano y cuñada. $A$ lo largo de la temporada, se irá relacionando con múltiples personajes con el fin de cumplir con su objetivo de alcanzar la libertad e irá desarrollando una historia de amor con la trabajadora social de la cárcel Ema (Martina Gusmán). Si bien en la serie aparecen distintos personajes, a los fines de este análisis identificaremos a los principales dentro de la cárcel San Onofre de la siguiente manera:

-Banda de "Los Borges": el líder es Mario Borges (Claudio Rissi), un hombre adulto (alrededor de sesenta años) que maneja la "mafia carcelaria" es decir vende droga, bebidas alcohólicas, celulares y diversos productos, con la connivencia de las autoridades de la prisión. Su hermano menor, es el joven adulto "Diosito" (Nicolás Furtado) quien es su principal secuaz. Aparecen también, menos individualizados, otros adultos que forman parte de la banda.

-Banda de "La sub 21": de acuerdo a su nombre se trata de una banda conformada por jóvenes entre 18 y 21 años de edad, su líder es César (Abel Ayala). La banda está presente en distintas unidades carcelarias. Sus otros integrantes están menos individualizados en la serie. Residen en el patio de la cárcel, en un espacio denominado "la villa".

-El Servicio Penitenciario: el director de la cárcel es Antín (Gerardo Romano), un hombre adulto (entre cincuenta y sesenta años) que coordina la institución. Se maneja de forma corrupta y en connivencia con los internos. Dirige a la guardia de seguridad conformada por hombres adultos en su totalidad, al equipo profesional y a su secretaria. Estos también mantienen relaciones irregulares y/o de connivencia con los internos. Esta tercera grupalidad de personajes, tiene la particularidad de operar como "bisagra" o "nexo" entre las dos bandas. En primer lugar Antín, manipula a ambas bandas por medio de interacciones principalmente con Mario Borges y con 
"Pastor" para mantener el orden y la distribución del poder entre ambas facciones, lo cual le permite a él como director mantener el control del penal. A su vez los guardias de seguridad son quienes "habilitan" las distintas secuencias de violencia que se dan entre bandas, como mencionaremos más adelante.

Nos centraremos en el análisis y tratamiento de la banda sub-21 y de su líder César, para indagar en torno a las representaciones sobre la juventud, la masculinidad y la transgresión.

En el primer capítulo llega "Pastor" a la cárcel de San Onofre y lo ubican en el patio, "la Villa". Se trata de un patio interno rodeado por los pabellones de la cárcel, al aire libre, en el cual hay casillas de cartón y chapas que conforman los lugares de alojamiento de los internos. Allí tiene un encontronazo con Morcilla (Carlos Portaluppi), el "encargado" de la Villa, miembro de la banda de "Los Borges". Tras este conflicto, Morcilla va al pabellón del líder de su banda y le solicita a Mario Borges que se tomen acciones al respecto. Este se niega y le recrimina a Morcilla estar exigiéndoles a las familiares de otros internos que le deben dinero, tener relaciones sexuales. Pero le aclara que se lo va a dejar pasar porque:

Mario Borges: Si no fuera por nosotros, los pendejos de la sub-21 estarían gobernando la villa, ¿sabes lo que sería esto?

Otro miembro de la banda, James (Daniel Pacheco Bautista), le dice que deberían de colgarlos en el patio para que aprendan, como se hace en su país Colombia. El líder le contesta:

Mario Borges: Yo no quiero un país donde los pendejos se estén cagando a tiros, toda esta puta herencia de hacerse los mafiosos viene de los gringos de mierda que ustedes y los mexicanos se la pasan imitando.

Esta escena transcurre alrededor del minuto 10 del capítulo 101. Es decir que desde el principio se va a presentar a la banda de los jóvenes como opuesta a la de los adultos. No solo en términos de rivalidad, sino también a partir de la modalidad de acción de cada cual. Los Borges estarán vinculados al crimen organizado, meticuloso y en connivencia con las autoridades. Y la Sub-21 más vinculada a la violencia desorganizada y espontánea, con menos poder y contactos (al menos al comienzo de la serie). Esto se refuerza hacia el final de este capítulo cuando los jóvenes revisan las pertenencias de otro interno recientemente asesinado, se muestran jocosos y divertidos. De repente un joven bromea a otro y este se enoja, saca una faca (cuchilla hecha con objetos punzantes diversos) y empiezan a forcejear enojados, el resto 
se mete a separar. Pastor lo mira al "Tatuador", otro adulto, allí presente y le dice en tono despectivo: ¿están siempre así estos pibes?

Al comienzo del capítulo 102, Pastor sale de una celda de aislamiento (castigado por su conflicto con Morcilla) y busca a los jóvenes en la casilla del tatuador.

Pastor: ¿sabes dónde están los de la sub 21?

Tatuador: ¿César y sus drogadictos?

Interno tatuado: alto nombre para una banda.

Aparece nuevamente la caracterización peyorativa del grupo, sumando a la violencia descontrolada el consumo problemático de drogas.

Esta diferenciación de los jóvenes y los adultos, no solo desde la rivalidad sino desde la jerarquización diferencial nos permite comenzar a observar la diversidad de experiencias masculinas. Es decir, entre los hombres existen relaciones de poder y dominación a partir de la intersección del género con otras dimensiones como la condición social y la edad o generación. Cuando Pastor los encuentra, se alegran de verlo y comienzan a cantar:

Volvió el loquito más picante del condado, volvió enojado.

El que se coje la Morcilla de parado, y saca el choto todo cagado.

Acá en el patio no queremos refugiados, sub-21, somos soldados.

Aquí aparece una autodefinición como "soldados" haciendo referencia a la lealtad y a los "códigos" que ellos afirman tener. A su vez aparece la violencia sexual como marca de virilidad (lo desarrollaremos más adelante). Esta caracterización positiva respecto de si mismos estará presente en distintos momentos. Pastor saca provecho de esta lealtad que le muestran los jóvenes para lograr su objetivo de destituir a Morcilla, para ocupar él su lugar y ganar la confianza de los Borges. La Sub-21 rompe el candado de la casilla donde se guardan los artículos de consumo como alcohol, drogas, tarjetas de teléfono y comida para festejar el cumpleaños de César.

A continuación se muestran escenas en la que se los ve bebiendo, fumando, aspirando cocaína, teniendo sexo con otros internos trans (2). Esto deviene en el armado de un muñeco al cual denominaran Morcilla y prenderán fuego gritando y saltando alrededor (figura 1). 


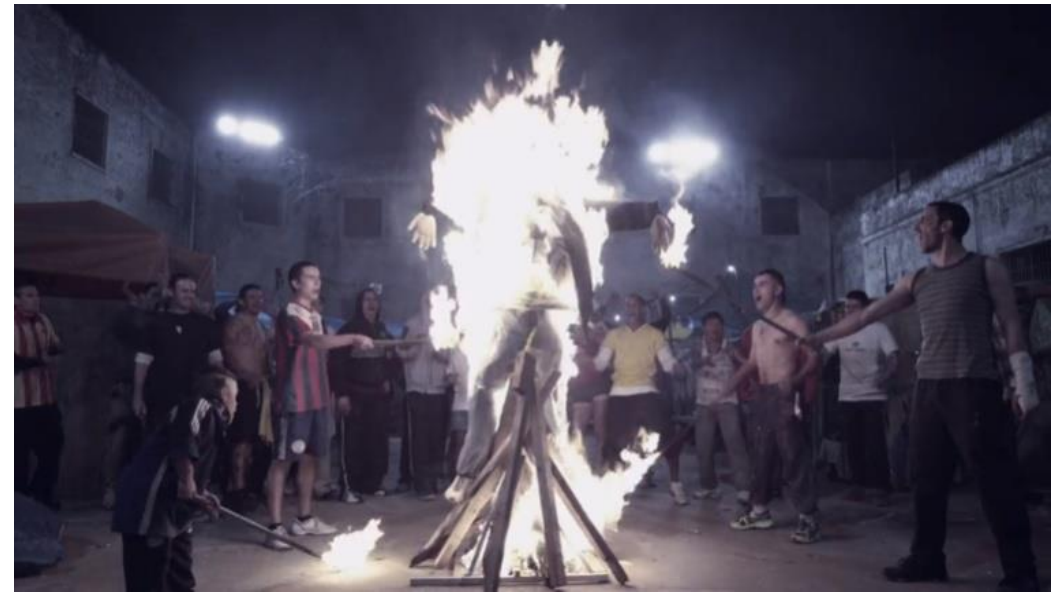

Figura 1: sub-21 y Pastor prendiendo fuego a muñeco, escena 102. Fuente: Serie El Marginal, Netflix (2018).

Al ver por primera vez como espectadores/asesta escena (Figura 1) se nos presenta la imagen estereotipada de sociedades primitivas alrededor del fuego y con la concepción -evolucionista (Boivin, et al. 2004)- de estas como "salvajes" en tanto cercanas a la naturaleza y/o lo animal. Esta técnica retorica utilizada en esta escena supone una inducción lógica que no es científica, sino "pública" (Barthes, 1970) en la cual se van encadenando ideas, palabras o hechos, de manera implícita con el fin de transmitir un contenido determinado.

En el análisis de la serie argentina "Policías en Acción" (Contursi y Arzeno, 2009) -centrada en hechos delictivos "reales" en el conurbano bonaerense- se sostiene que los sectores populares son presentados desde una mirada "miserabilista" desde la cual carecen de racionalidad, a su vez se transmite la idea de que en el conurbano todos los escenarios son iguales y reina "el caos". Afirman que "Es ahí donde se pone en escena la idea de que los pobres del conurbano gozan de la libertad de los salvajes, alejados de cualquier trama de socialización" (Ídem). En este sentido, retomo a dichos autores para analizar la escena (Figura 1) de El Marginal la existencia de un topo omnipresente:

(...) la animalización de los pobres (se muestra el territorio y sus habitantes como caóticos, salvajes que no saben ni hablar, promiscuos que se encuentran en estado de anomia, sin propiedad privada, sus residencias parecen madrigueras vulnerables, no hay límites entre vecinos, la gente aparece apabullada o alcoholizada o drogada o eufórica, no hay rastros de racionalidad). Se construye un enunciatario racional de clase media a quien se dedica el mensaje de que las clases subalternas en su caos representan una amenaza, incluso para ellas mismas (Contursi y Arzeno, 2009). 
Agustín Martinuzzi (2011) analiza las representaciones mediáticas de jóvenes "en situación de delito" en los principales diarios de la Región Centro de la Argentina y encuentra algunos elementos recurrentes similares a los que hemos mencionado como el hecho de que los jóvenes sean inseguros, peligrosos y promotores del riesgo. En las noticias analizadas da cuenta de la caracterización de las transgresiones como poco planificadas, con objetivos pequeños y fuertemente violentas en las que se reitera una frase ya instalada en el sentido común: "Si al joven delincuente no le importa poner en juego su propia vida menos le va a importar la vida de los demás" (2011).

Toda esta caracterización que se hace de la sub-21, en tanto banda de jóvenes varones, que se compara con la banda rival de adultos Los Borges nos remite a la dicotomía clásica racional/emocional en tanto conceptos antagónicos culturales que en general se presentan como conceptos opuestos, exhaustivos y excluyentes entre sí (Maffia, 2013). Pareciera que los jóvenes actúan emocionalmente y los adultos racionalmente. Este par antagónico, junto a otros tales como objetivo/subjetivo, mente/cuerpo, etcétera, está jerarquizado. Esto significa que nuestra sociedad valora positivamente las actitudes racionales por sobre las emocionales. A su vez están sexualizados, es decir, se asocia estereotipadamente lo racional a lo masculino y lo emocional a lo femenino. Siguiendo esta línea de pensamiento, tomamos los aportes de Connel para pensar las relaciones de poder entre los varones, y nos encontramos con que al interior del mundo carcelario están representadas masculinidades hegemónicas en los adultos que pertenecen a la banda Los Borges y en los jóvenes de la sub-21, masculinidades más bien subordinadas (vinculando lo emocional a lo femenino) y/o marginales (vinculado a su condición de "villeros"). En este sentido, sostenemos que "el patriarcado existe no sólo como un sistema de poder de los hombres sobre las mujeres, sino de jerarquías de poder entre distintos grupos de hombres y también entre diferentes masculinidades" (Kaufmann, 1997: 4).

A lo largo de la serie, los espectadores y espectadoras podrán observar como este orden se va modificando levemente cuando César comienza a tomar medidas más planificadas y Mario Borges a actuar más explosivamente. Cabe destacar que las acciones del primero estarán atravesadas por la manipulación de Pastor quien se posiciona como aliado de la sub-21, con el fin de obtener su objetivo personal. A su vez, las acciones más explosivas de la banda de Los Borges serán lo que los lleve hacia el declive de su status carcelario. 


\section{El espacio físico y social: los jóvenes en la villa, los adultos en el pabellón}

En primer lugar cabe destacar que prácticamente toda la serie transcurre dentro de la Cárcel San Onofre. Es interesante destacar que en la búsqueda de verosimilitud la serie fue filmada en la ex cárcel de Caseros -de modelo panóptico- situada en la ciudad de Buenos Aires y cerrada en 2001. En la misma también se filmó la serie Tumberos (América TV, 2002) dirigida y creada igualmente por Adrián Caetano y Sebastián Ortega.

La cárcel es un espacio físico desconocido y conocido a la vez. Podemos decir que es desconocido, ya que la mayoría de la población jamás entro a una cárcel, no es un lugar al que se pueda ir "a conocer", su acceso está restringido. Pero también es conocido a partir de sus representaciones, en especial aquellas provenientes de los medios masivos de comunicación por medio de su capacidad de refracción de la realidad como mencionamos al comienzo.

Tomaremos la cárcel como un territorio (des)conocido, y en esa tensión entre lo que se sabe y lo que no se sabe se imbrica fuertemente un estigma. Kessler (2012), siguiendo a Link y Phelan (2001) señala que hay estigma cuando en el marco de relaciones de poder se imbrican las etiquetas, estereotipos, separaciones, pérdida de status y discriminación. Por ende podemos pensar al analizar las cárceles que nos encontramos ante un territorio estigmatizado: "una de las características del estigma territorial es que se ordena en forma de pares opuestos y alteridades excluyentes (...)" (Kessler, 2012: 179). El par opuesto y excluyente es evidente: adentro/afuera; libres/presos.

Pero la serie no solo nos plantea este primer par opuesto territorial, sino que dentro del territorio estigmatizado de la cárcel nos encontramos con sub-territorios donde residen los internos: la villa/los pabellones.

Como hemos mencionado la sub-21 habita en el patio de la cárcel, en un asentamiento precario denominado "la villa". En la Argentina la villa "aparece fundamentalmente como una referencia negativa dentro de las representaciones urbanas, expresando el ámbito de residencia de una población considerada «marginal»" (Merklen, 1997: 3), se caracteriza por las condiciones precarias de la vivienda, el hacinamiento, la falta de acceso a servicios básicos (agua corriente, gas, luz, cloacas). Si bien se asocian a espacios de lucha y compromiso social, impera fuertemente en el sentido común el estigma de su población. 

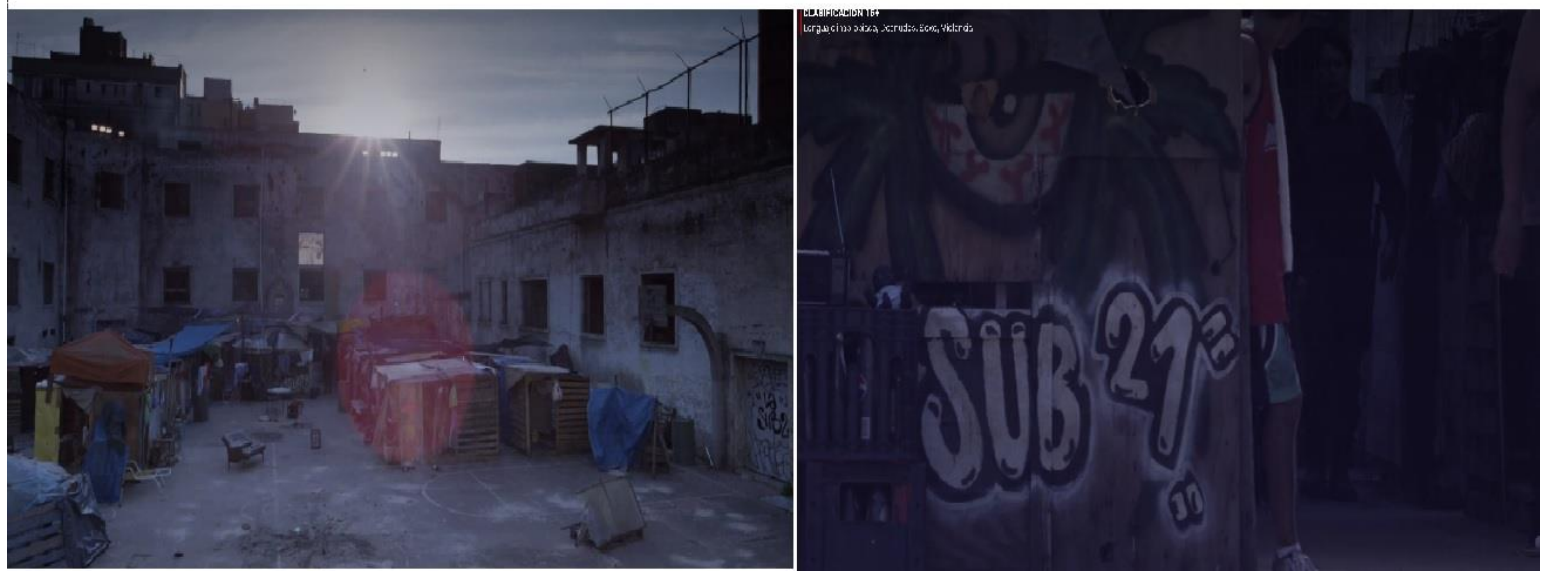

Figura 2: la Villa y grafitti de sub-21. Fuente: Serie El Marginal, Netflix (2018).

El pabellón que ocupan Los Borges cuenta con algunas comodidades por estar en connivencia con las autoridades tales como televisión led de 40 pulgadas, playstation, entre otras. En este sentido, el espacio físico opuesto y jerárquicamente diferenciado "(...) funciona como una especie de simbolización espontanea del espacio social" (Bourdieu, 1999:120).

\section{Las relaciones de dominación, sexualidad y afectos}

A lo largo de toda la serie, absolutamente todos los hombres dentro de la cárcel de San Onofre utilizarán permanentemente como forma de agredir y de posicionarse en un lugar superior términos que remiten a lo femenino y la homosexualidad. A este respecto es más que evidente que la forma en la que la serie represente el poder masculino hegemónico es por medio de la subordinación de las mujeres y los homosexuales.

En primer lugar, hay pocos personajes de mujeres relevantes en la historia. $Y$ en segundo lugar, todas las mujeres que trabajan o concurren a la cárcel San Onofre tienen una relación sexo/afectiva con los personajes principales. A su vez, las escasas conversaciones entre mujeres versan sobre lo atractivo de los internos. En el capítulo 107, Lucrecia (Adriana Salonia), la secretaria de Antín, comenta con las otras profesionales que los presos son "carne fresca las 24 horas a disposición" y "los amantes ideales" y recuerda haber tenido distintas experiencias sexuales con presos, como vemos en distintos capítulos con Mario Borges. Las tres mujeres que trabajan en San Onofre tienen acercamientos sexuales dentro de la cárcel. Pareciera que las mujeres no pueden escindir su vida profesional de la sexual/emocional. Tanto en el cine como en las series el protagonismo (y la dirección) es mayoritariamente 
masculina. Eso supone que el varón es el sujeto genuino, el "yo ideal", es quien encarna el relato y guía a los/as espectadores/as. Esto tiene consecuencias, tales como la "inanidad de las mujeres" (Aguilar, 2015), siendo estas secundarias, objeto de deseo, dóciles y de no serlo, molestas. A su vez el relato audiovisual simplifica la realidad e inclusive sostiene posicionamientos que ya han sido problematizado socialmente como el de la mujer objeto sexual.

Cabe destacar que estas tres mujeres interactúan principalmente con los varones adultos. A excepción de una única escena en la cual la trabajadora social Ema entrevista a César. Este es un momento interesante, ya que es el único en toda la serie que nos muestra otro matiz del joven personaje ya que habla de su familia, de sus preocupaciones. A su vez nos muestra por única vez una pequeña representación del contexto y las problemáticas sociales:

Cesar: sí, hablo (por teléfono con su familia) pero afuera está más jodido que acá dentro.

Ema: ¿Qué querés decir con eso?

César: Que mi vieja esta con una banda de quilombos, encima mis hermanos están en cualquiera, dejaron la escuela, están vendiendo merca (cocaína), mi mamá se enteró, les dijo que se dejen de joder (portarse mal) pero los guachos (chicos) no quieren hacer nada, encima están metidos con la cana (policía). Mi mamá esta partida al medio, imagínate.

Ema: ¿Vos tenés papá?

César: si, pero murió cuando éramos guachos.

Ema: ¿Tu mamá tiene trabajo?

César: limpia casas, no le alcanza para nada, encima ahora tiene a los mellizos y esta re ocupada. Por eso no viene.

Ema: vos los podes ayudar, incluso estando acá dentro. Digo, no sólo desde lo económico, sino desde la contención, por más que ellos no puedan venir los podes llamar por teléfono.

César: sí, ya sé.

Ema: sos un pilar muy importante para tu familia...

César: (sonríe) mirá si yo llego a terminar la escuela antes que mis hermanos (ambos ríen). (Figura 3). 


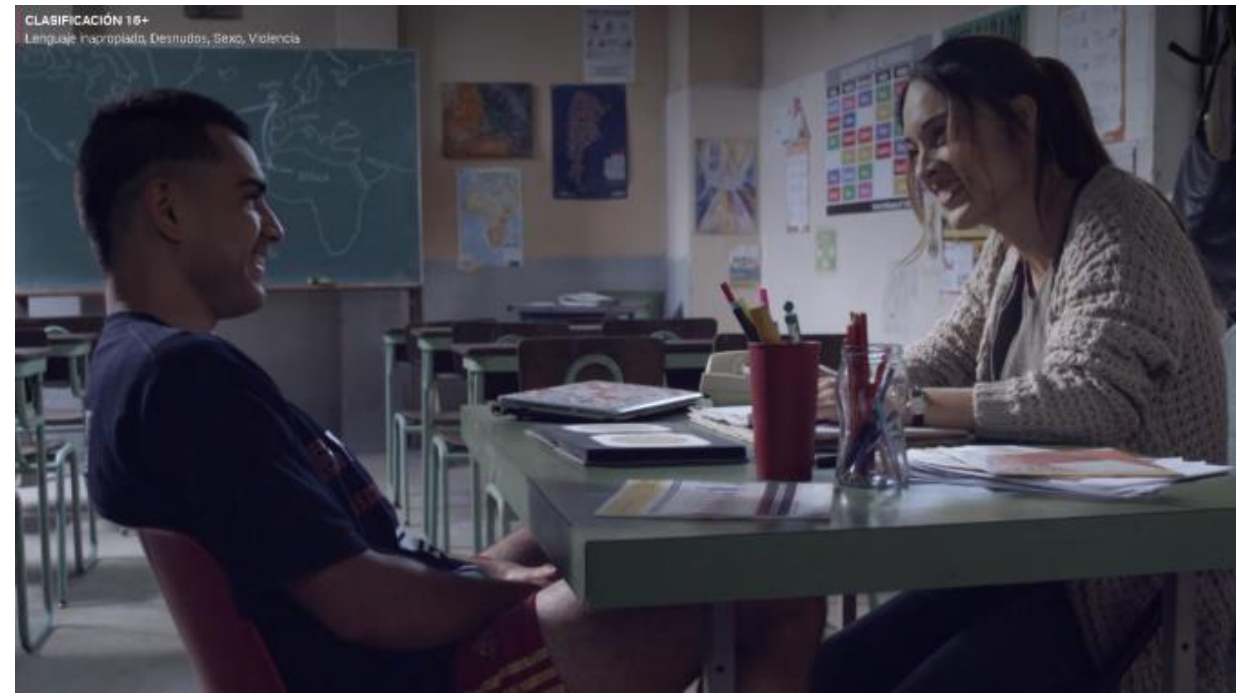

Figura 3: Entrevista de Ema a César, escena del capítulo 106. Fuente: Serie El Marginal, Netflix (2018).

Cabe destacar que no hay conversaciones de esta índole entre los jóvenes, ni entre otros internos. $Y$ finalmente, si bien en ningún momento César pretende intimidar o acercarse físicamente a Ema (como lo vemos con otros internos), esta conversación finaliza con César que le dice: "Qué linda que es" y Ema sonriendo. Aun con respeto y en el marco de una conversación relevante, las relaciones entre varones y mujeres están mediatizadas por lo sexual.

Aparecen también personajes trans -cabe destacar que no podemos siquiera hacer referencia a como se auto perciben o denominan estos personajes, ya que prácticamente no tienen diáogo- fuertemente asociados a las actividades sexuales de los personajes principales; en este sentido no se presentan como relaciones de pares sino como objetos sexuales de los varones, como se observa en el cumpleaños de César, en el capítulo mencionado anteriormente.

Finalmente entre los presos hombres, como mencionamos al comienzo de este apartado, permanentemente hacen referencia a la homosexualidad para agredirse, como así también respecto de la violación carcelaria, la canción que cantaba la sub-21 es uno de tantos ejemplos.

No sólo la dominación sexual como amenaza o insulto, sino como hecho concreto que ocurre como venganza ante un conflicto y habilitado por los guardias de seguridad -como mencionamos anteriormente. La banda de Los Borges viola a César en las duchas (Figura 4), tras el hecho el joven llora en el piso del baño hasta que llega Pastor y lo socorre. 


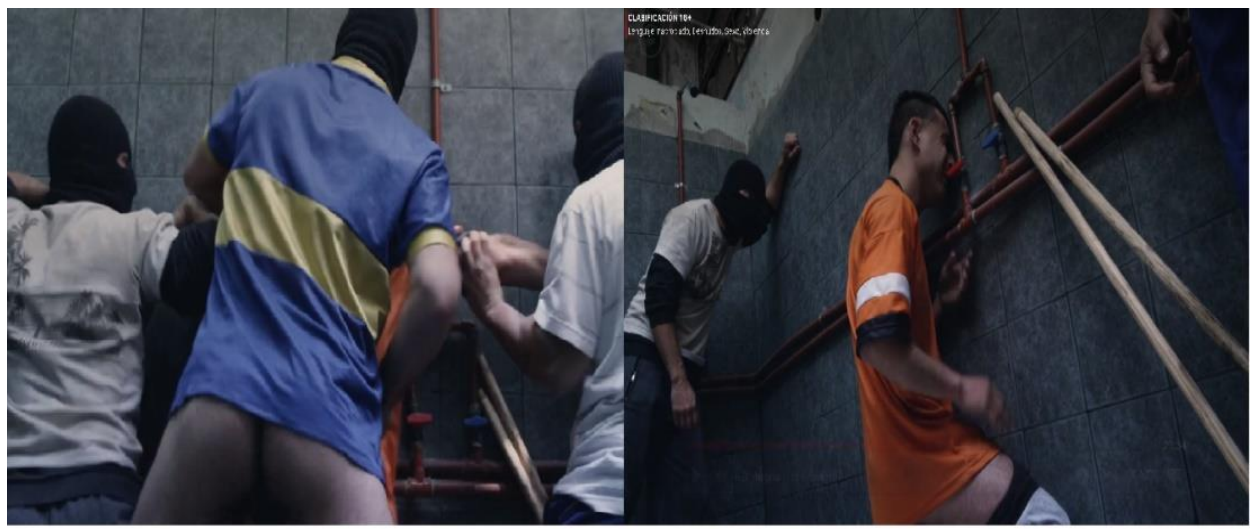

Figura 4: violación de César, escena del capítulo 109. Fuente: Serie El Marginal, Netflix (2018).

La violación sexual y cruenta como acción disciplinadora (Segato, 2010) se ejecuta mayoritariamente contra las mujeres. En este caso, podemos pensar cómo esta violación disciplina a un joven que quiere ocupar el lugar de poder de otro hombre, y este lo "feminiza" por medio de la violación. A César, y otros presos, lo veremos recibir golpizas y cuchillazos, pero solo lo veremos llorar ante este hecho. A la agresión física se le suma la connotación simbólica de este tipo de agresiones. A continuación, en la serie, él hará referencia únicamente a que lo "cagaron a palos en las duchas", ocultando la violación.

Cabe destacar, como uno de los poco matices que aparecen en la serie respecto de las relaciones sexo/afectivas de los protagonistas, al personaje de "Diosito". Si bien no pertenece a la sub-21, grupo objeto de análisis de este trabajo, es el único personaje con rol protagónico, que despliega una sexualidad y afectividad homosexual. Los sentimientos sexo/afectivos de "Diosito" hacia Pastor son presentados como conflictivos para este personaje, quien también apela al sexismo recurrentemente. De esta manera, las relaciones sexuales entre hombres aparecen no sólo como una amenaza de dominación, sino como una posible interacción afectiva por fuera de la heteronormatividad. En este sentido, hacia el final de la serie, Pastor se aprovecha de estos sentimientos que son experimentados de manera conflictiva por "Diosito", para que este confíe en él. Nuevamente, pero desde otro ángulo, la masculinidad homosexual queda subordinada a la hegemónica, ya no por medio de la dominación sexual, sino mediante la manipulación afectiva. 


\section{Reflexiones finales}

El mundo carcelario representado en la serie El Marginal es sumamente violento y estereotipado. Entendemos que es estereotipado en base a dos elementos: la simplificación y la generalización. El primer elemento refiere a la "(...) elección de elementos específicos, de omisiones conscientes y de simples olvidos" (Perrot y Preiswerk, 1979). El mundo carcelario se simplifica en torno a elementos tales como la violencia física, la corrupción y el sexismo. La generalización da cuenta de la falta de matices, todos los personajes son en mayor o menor medida iguales. Más allá de las diferencias entre adultos y jóvenes, y entre presos y guardias, todos son violentos, corruptos y sexistas. Por su parte, las mujeres y personas trans están sexualizadas y al servicio de los personajes masculinos.

Dentro de esta imagen estereotipada del mundo carcelario, se construye otra representación que es la de los jóvenes como volátiles, peligrosos, marginales (aún más que el resto) y con poco poder. Aunque podemos decir también que César aparece como uno de los personajes más "entrañables" en esta ficción ya que su violencia parece más bien reactiva a las violencias ajenas, no se lo ve maltratando a las mujeres ni a quienes no lo agreden. Este matiz es muy poco desarrollado, ya que destacan más elocuentemente sus acciones vengativas (asesinato, desmembramiento, electrocución).

Esta aproximación a las representaciones de las juventudes y masculinidades en contexto de encierro en la serie El Marginal es relevante ya que nos permite ver cómo construye nuestra sociedad su imaginario en torno a esta población. En este sentido,

\footnotetext{
(...) las ficciones audiovisuales (tanto las cinematográficas como las televisas) siguen siendo uno de los pilares básicos de la construcción del imaginario social y, por eso mismo, una de las principales herramientas en el cambio de mentalidad que se está operando en la construcción de las nuevas masculinidades. No en vano es un trabajo arduo que necesita referentes ya que se propone desmontar toda la mitificación de la masculinidad y la heterosexualidad normativa operada por el patriarcado y acomodarla a una realidad donde la mujer es un sujeto activo a nivel personal, social, económico, profesional, político, cultural y sexual (Zurian, 2008: 49).
}

Consideramos que esta forma de representar aspectos tan sensibles de nuestra sociedad como lo son la cárcel, sus trabajadores y trabajadoras y las personas privadas de su libertad, contribuye a la estigmatización de los mismos y no aportan a la comprensión social de la realidad como un todo complejo. No puede dejar de leerse esto en el contexto de 
recrudecimiento del discurso de la inseguridad y de la exigencia de "mano dura" por parte del gobierno actual y la población general. En este respecto, son los jóvenes los principales estigmatizados, criminalizados y perseguidos.

Ante la pregunta por la relación entre las problemáticas y condiciones sociales reales de los jóvenes en conflicto con la ley y su representación en la ficción, la cual ha motivado la elaboración de este artículo como mencionamos al inicio, escojo para finalizar este trabajo recuperar la voz del joven cineasta Cesar González (quien tuvo un papel mínimo en esta serie del cual ha manifestado arrepentirse):

\begin{abstract}
Ninguna ficción es inocente. Si me aclararan que esta serie es un producto de humor bizarro no tendría ningún problema. El problema surge cuando la presentan como una serie seria que "muestra la realidad" y mucha gente creerá que así de ridículos y caricaturescos son los presos. Que a mi entender y a partir de mi experiencia de cinco años preso, de tener un hermano, primos y multitud de amigos tras las rejas, no se parecen en nada a los presos que muestra esta serie. Los presos que yo conocí y conozco desbordan seriedad, lucidez y gestos de una solidaridad que pocas veces encontré en las personas aquí afuera. Gestos que no vi en casi ningún personaje de la primer temporada (...) (3).
\end{abstract}

\title{
Notas
}

(1) La tesis aprobada en 2017 se titula La construcción de maculinidad(es) y su relación con la vulnerabilidad penal juvenil. Un estudio socio-antropológico con perspectiva de género. Se encuentra disponible en la Facultad Latinoamericana de Ciencias Sociales (FLACSO), Sede Argentina.

(3) "Ojalá algún día"; la crítica de César González a "El Marginal". Conclusión, 23 de abril de 2018. Recuperado de http://www.conclusion.com.ar/espectaculos/ojala-algun-dia-la-critica-de-cesar-gonzalez-a-el-marginal/04/2018/

\section{Bibliografía}

Aguilar, P. (2015). La ficción audiovisual como instrumento de educación sentimental en la modernidad. En Almudena, H. (ed.). Mujeres, hombres, poder. Subjetividades en conflicto (pp. 35-53). Madrid: Traficantes de Sueños.

Barthes, R. (1970). Recherches rhétoriques. En López, M.; Rosolla, E. y Amato Negri, L. (2002). El discurso de propaganda. Persuadir para el bien social. Buenos Aires: Proyecto Editorial. 
Boivin, M.; Rosato, A. y Arribas, V. (2004). Constructores de otredad. Buenos Aires: Antropofagia.

Bourdieu, P. (1999). La miseria del mundo. México: FCE.

Connell, R. W. (1997). La organización social de la masculinidad. En Valdés, T. y Olavarría, J. (ed.). Masculinidad/es: poder y crisis (pp. 31-48). Santiago, Chile: ISIS-FLACSO.

Contursi, M. E. y Arzeno, F. (2009). Policías en acción: género y representaciones de la violencia. Question, 1(22).

Cremona, F. y Ficoseco, V. S. (2015). Showmatch. La espectacularización de la masculinidad en un mundo de paradigmas en crisis. Question, 1(47), invierno. Recuperado de https://perio.unlp.edu.ar/ojs/index.php/question/article/view/2608

Crenshaw, K. W. (1991). Mappingthe Margins: Intersectionality, IdentityPolitics, and Violence against Women of Color. Stanford LawReview, 43(6), pp. 1241-1299.

De Lauretis, T. (1992). Alicia ya no. Feminismo, semiótica y cine. Madrid: Editorial Cátedra.

Expósito Molina, C. (2012). ¿Qué es eso de la interseccionalidad? Aproximación al tratamiento de la diversidad desde la perspectiva de género en España. Investigaciones Feministas, 3, pp. 203-222.

Fernández, M. C. (2012). Juventudes, delincuencia y castigo. Un estudio de caso en noticieros de televisión. Question, 1(34), otoño, pp. 118-130. Recuperado de https://perio.unlp.edu.ar/ojs/index.php/question/article/view/1429

Ferreiro Habra, A. C. (2018). Masculinidades en el discurso publicitario. Question, 1(58), otoño. Recuperado de https://perio.unlp.edu.ar/ojs/index.php/question/article/view/4608

Zurian, F. A. (2015). Diseccionando a Adán. Representaciones audiovisuales de la Masculinidad. Madrid: Editorial Síntesis.

Grau Rebollo, J. (2005). Antropología, cine y refracción. Los textos fílmicos como documentos etnográficos. Gazeta de Antropología, 21(3), pp. 1-18.

Guarinos, V. (2013). Hombres en serie: construcción de la masculinidad en los personajes de ficción seriada española de televisión. Madrid: Fragua.

Guarinos, V. (2015). El país de los hombres perdidos. Personajes masculinos en el abismo en el cine español de la transición. Área Abierta, 15(1). Recuperado de file://C:/Users/Cecilia/Downloads/47615-82647-1-PB.pdf

Hopenhayn, M. (1999). La aldea global entre la utopía transcultural y la ratio mercantil, en Degregori, C. y Portocarrero, G. (eds.). Cultura y Globalización, Lima, Red para el Desarrollo de las Ciencias Sociales en el Peru, pág. 17-36.

Instituto Nacional de Estadísticas y Censos (INDEC) (2012). Encuesta Nacional sobre Acceso y Uso de Tecnologías de la Información y la Comunicación. Resultados del tercer 
Julieta Nebra. Juventud(es) y masculinidad(es) en la serie televisiva El Marginal. Un análisis socio-antropológico con perspectiva de género

trimestre de 2011. Recuperado de https://www.indec.gov.ar/uploads/informesdeprensa/entic_12_12.pdf

Kaufmann, M. (1997). Los hombres, el feminismo y las experiencias contradictorias del poder entre los hombres. En Valdés, T. y Olavarría, J. (Eds.). Masculinidad/es. Santiago de Chile, ISIS/ FLACSO.

Koziner, N. (2014). Ni víctimas ni victimarios. Juventud y violencia en los medios masivos de comunicación. Question, 1(42). Recuperado de https://perio.unlp.edu.ar/ojs/index.php/question/article/view/2113/0

Maffía, D. (2013). Contra las dicotomías: feminismo y epistemología crítica. Instituto Interdisciplinario de Estudios de Género, Buenos Aires, Universidad de Buenos Aires. Recuperado de https://bit.ly/104G1pa

Martinuzzi, A. (2011). Representaciones mediáticas de "la juventud en situación de delito". Lo policial como marco de inteligibilidad para las culturas juveniles contemporáneas. Observatorio de Jóvenes, Comunicación y Medios, Facultad de Periodismo y Comunicación UNLP. Recuperado de www.perio.unlp.edu.ar/observatoriodejovenes/sites/perio.unlp.edu.ar.observatoriodejov enes

Merklen, D. (1997). Organización comunitaria y práctica política. Las ocupaciones de tierras en el conurbano de Buenos Aires. Nueva Sociedad, 149, pp. 162-177.

Parchuc, J. P. (2015). La Universidad en la cárcel: teoría, debates, acciones. Redes de Extensión, 1, pp. 18-36.

Perrot, D. y Preiswerk, R. (1979). Etnocentrismo e historia. México DF: Ed. Nueva Imagen.

Scott, J. (1996). El género: una categoría útil para el análisis histórico. En Lamas, M. (Comp.). El género: la construcción cultural de la diferencia sexual (pp. 265-302). México: PUEG.

Segato, R. (2007). El color de la cárcel en América Latina. Apuntes sobre la colonialidad de la justicia en un continente en desconstrucción. Nueva Sociedad, 208, pp. 142-161.

Segato, R. (2010). Las estructuras elementales de la violencia: ensayos sobre género entre la antropología, el psicoanálisis y los derechos humanos. Buenos Aires: Prometeo Libros.

Zurian, F. (2011). Héroes, machos o simplemente hombres: una mirada a la representación de las (nuevas) masculinidades. Secuencias, 34, pp.32-53. 